\title{
Metáforas del cuerpo: el lenguaje artístico como recurso de la memoria*
}

\author{
Josefina Dobinger-Álvarez Quioto**
}

Recibido: marzo 30 de 2016 • Evaluado: abril 8 de 2016

Aceptado: abril 22 de 2016

\section{Resumen}

Este artículo analiza el trabajo realizado por la organización hondureña Mujeres en las Artes (MUA) durante los últimos 20 años. A partir de relatos de vida y de creaciones artísticas, como representación, interpretación y explicación del mundo cotidiano, se considera al cuerpo como territorio, como metáfora que agencia procesos personales y colectivos que hacen del lenguaje artístico un auxiliar de la memoria y una vía para brindar sentido a la existencia. Así, la violencia, el trauma, la huella, el olvido y el silencio

" El presente estudio es resultado de una propuesta teórica, investigativa y expositiva de la Sala Mujeres del Arte Contemporáneo (SMAC) en el marco de la conmemoración de los 20 años de fundación de la organización hondureña Mujeres en las Artes "Leticia de Oyuela" MUA (1995-2015). Sin embargo, ya desde 2012, con el Encuentro de Mujeres Creadoras "Enlaces y presencias", MUA había iniciado la tarea de explorar el cuerpo como territorio de sentido, rescatando las vivencias de las mujeres creadoras y sus aportes en la ruta para hacer de Honduras el proyecto de una nación. El estudio fue financiado en su totalidad por Mujeres en las Artes (MUA), dio inicio el 19 de febrero de 2015 y finalizó el 16 de marzo de 2016 con las reflexiones sobre el proceso reunidas en el escrito Cartografías del alma. El cuerpo como archivos vivos de la memoria. http://issuu.com/publicacionesmua/docs/cartografiasv3/1. DOI: http://dx.doi.org/10.15332/s2248-4418.2016.0001.04

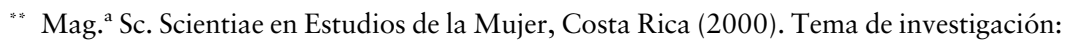
Mujeres centroamericanas y práctica artística: Interpretación de la realidad desde el lenguaje del arte. Un estudio de casos en Honduras y Costa Rica. Lic. En Historia, UNAH (1993). Diplomado en Educación y trabajo, Wirtschaftsförderungsinstitut der Wirtschaftskammer Wien WIFI, Viena (2007). Es cofundadora de Mujeres en las Artes "Leticia de Oyuela” MUA, y su directora hasta 1998. Consultora independiente e investigadora y curadora de la Sala SMAC hasta la actualidad. Correo electrónico: Chefydobingeralvarez@gmx.at 
se confrontan a los discursos paradigmáticos que sustentan la cultura y la ciencia y dan cuenta de un conocimiento, de un aprendizaje de las cosas que el cuerpo es capaz de explorar, como lo advierte Merleau Ponty.

Palabras clave: cuerpo como territorio; metáfora; memoria; violencia; trauma; huella; olvido; lenguaje artístico; creación artística; Mujeres en las Artes (MUA) 


\section{Metaphors of the body: the artistic language as resource of memory}

\section{Abstract}

This paper analyzes the work of the Honduran organization Mujeres en las Artes (MUA) - Women in the Arts - over the past 20 years. Starting from life stories and artistic creations - such as representation, interpretation and explanation of the everyday world - the body is considered as territory, as a metaphor that mediates personal and collective processes. Therefore, the artistic language endures memories and provides meaning to life. As a consequence, - violence, trauma, marks, oblivion and silence confront the paradigmatic discourses that support culture and science; declaiming for knowledge and learning of what the body is able to explore, as warned by Merleau Ponty.

Keywords: the body as territory; metaphor; memory; violence; trauma; marks; oblivion; silence; artistic language 


\section{Introducción}

Una novela, un poema, un cuadro, una pieza musical son individuos, es decir, seres en los que no puede distinguirse la expresión de lo expresado, cuyo sentido solo es accesible por un contacto directo y que irradian su significación sin abandonar su lugar temporal y espacial. Es en este sentido que nuestro cuerpo es comparable a la obra de arte. Es un mundo de significaciones vivientes.

Merleau-Ponty, Trilles, 2004, p. 4

La Organización Mujeres en las Artes "Leticia de Oyuela”, conocida como MUA, es una asociación civil de carácter cultural-educativa creada en Tegucigalpa, Honduras en el año 1995. Sus acciones se dirigen a evidenciar el papel activo de las mujeres en las artes. Por lo tanto, parte de la premisa de los significados sociales que se revelan en la experiencia corpórea son expresados a través del lenguaje artístico. Así, las mujeres artistas certifican lo que Merleau-Ponty (1936) llama la experiencia vivida, la vida que solo es posible vivirla si se penetra en ella, lo que hace posible nombrarla a partir de la reflexión crítica sobre ese estar en el mundo. Un mundo donde no existen caminos marcados, en acuerdo con Ponty, sino devenires que invitan a la travesía, ya que no hay mapas establecidos, sino territorios por cartografiar.

Como se mencionó anteriormente, MUA hace referencia a las experiencias vividas por las artistas, las cuales hablan de representaciones, interpretaciones y explicaciones respecto al mundo que se vive. Si se analiza lo anterior a partir de la cosmogonía de los pueblos prehispánicos y originales en su mixtura étnico/racial que caracteriza la región centroamericana, se hablaría de la búsqueda por registrar las vivencias de las artistas, tal como lo hicieron los pobladores originales con el registro astrológico dirigido a inventariar los movimientos de los astros, cuyo objetivo primario era, a partir del conocimiento de los fenómenos, poder programar actividades colectivas y realizar ceremonias orientadas a conjurar el caos y la destrucción.

El entorno hondureño dentro del cual nace MUA es marcado por profundos sentimientos de desconcierto, lo que la escritora De Oyuela ${ }^{1}$ (2001)

1 Leticia de Oyuela. Tegucigalpa (1935-2008). Destacada escritora e historiadora. Escribió más de 25 libros, múltiples ensayos y artículos sobre la historia de Honduras, la vida cotidiana, historiografía de las artes en Honduras y el papel de la mujer en la sociedad, las artes y la cultura. 
describe como sentimientos de vacuidad que se ubican en el espacio interior y que dan paso a la angustia existencial instalada en el imaginario popular como la pérdida agobiante de las grandes utopías, de la profesión de fe y de la gran necesidad de creer (p. 2).

Han sido esos sentimientos de vacuidad, de vacío, los que vendrían a representar la huella de la violencia, carente de una marca que evidencie los hechos violentos. Lo anterior se percibe cuando la capacidad de rememorar se paraliza en la persona o en los colectivos sociales sobre todo ante la ausencia de heridas y cicatrices, pero que, aun así, los acontecimientos violentos y traumáticos quedan tatuados o estampados como huellas mnémicas en el cuerpo de las personas y, por lo tanto, en el cuerpo social.

Durante los últimos 20 años se ha desarrollado un incremento estremecedor de la desigualdad estructural y la inequidad social en todo el territorio hondureño. Actualmente el país cuenta con aproximadamente 8.5 millones de habitantes, y más del $67.4 \%$ son menores de 30 años $^{2}$, sin entrar en detalle sobre los jóvenes, niñas y niños que emigran, mayoritariamente, hacia los Estados Unidos, sumados a ellos los que son asesinados o los que mueren de inanición/hambre. Además, se ha vuelto un agravante que, a partir del año 2010, Honduras se haya convertido en una de las zonas más violentas y peligrosas del mundo. Según el informe de la Comisión Interamericana de Derechos Humanos (CIDH, 2015), "la violencia y la inseguridad son problemas graves a los que se enfrenta la sociedad hondureña, con grandes repercusiones en el goce y ejercicio efectivo de los derechos humanos", apunta a su vez que: "en el 2013, el índice de homicidio en Honduras fue el más alto a nivel mundial” (p.11).

Durante la década de los noventa, se podría describir la sociedad hondureña como una población desestructurada y desocializada (Touraine, 2005), ${ }^{3}$ la cual se distinguió por atravesar una aguda crisis de sentido que era percibida como una amenaza innombrable, donde el tejido social no era capaz de proveer a la ciudadanía las herramientas necesarias para alcanzar

2 Véase referencia: datos estadísticos de la OIT para la promoción del empleo juvenil en América Latina en su apartado, Honduras.

3 Para Alaine Touraine (2005) hoy en día lo que existen son sociedades desestructuradas y desocializadas. Touraine dice que tenemos que aceptar la desaparición de todo vínculo social, ya que actualmente la sociedad tiende a una homogenización que trata de eliminar cualquier resquicio de identidad. 
sus metas. La actividad pública y la esfera de la vida familiar, social y colectiva se vieron saturadas, sobre todo en las ciudades, por el incremento acelerado de la corrupción, la impunidad, la criminalidad juvenil, el desplazamiento violento de la poblacional del campo a la ciudad y por la violencia contra las mujeres, entre otros. Así, entre el año 2005 y el 2012, la muerte violenta de mujeres -feminicidios- en Honduras pasó de 175 a 606 en un aumento de un $246.3 \%$.

Es necesario destacar que durante la década de los ochenta se establece la violencia directa en Honduras y se institucionalizan, al implantar el miedo, la represión y las tensiones respecto a la libertad de expresión en el imaginario social de la población. "Profesionales de las Ciencias Sociales la nombran como la década perdida, por sus consecuencias funestas y, especialmente, por haber sido un periodo de ejecuciones, asesinatos y persecuciones de personas, en su mayoría disidentes o interlocutores críticos" (De Oyuela, 2001, p. 275).

Lo anterior alude, sin lugar a duda, al trauma desde su función ideológica, centrada en el ocultamiento, tal como lo ha visibilizado la teoría feminista respecto a los traumas privados, secretos e insidiosos, sobre todos aquellos vinculados a la violación y el acoso sexual. También refiere a traumas colectivos como la desaparición forzada y sus implicaciones devastadoras sobre el lenguaje, la identidad y el sentido.

Durante estos veinte años que MUA ha concretado la importancia de mantener activos los recuerdos, de enfatizar la envergadura que posee el tiempo, la memoria, la utopía, la esperanza y el derecho a la cultura, para poder comprender y explicar el pasado, sobre todo, aquello significativo que se elabora en función de una expectativa hacia futuro. Evidencia el papel activo de las artistas desde sus experiencias corpóreas, es decir, desde sus experiencias vividas al interior de la práctica artística, que se entiende como la ocupación habitual y constante en la que se desarrollan las experiencias del hacer artístico que abarca entre otros aspectos: la producción de objetos artísticos, el desarrollo de aptitudes a través del ensayo de técnicas, las modificaciones de la personalidad de las artistas y sus vinculaciones con las ideas y sentimientos de una colectividad social.

El cuerpo como territorio, como espacio geográfico-social, formulado originalmente por Merleau-Ponty, se nos descubre como un ser viviente orientado hacia el entorno que lo acoge, por lo que la presencia del cuerpo 
es fundamental para el mundo, pues es aquello que lo “oxigena”, que lo hace visible y lo transforma en percibido (Trilles, 2004. p. 137). El cuerpo vivido, para Ponty, advierte Trilles (2004) "da voz a una conciencia, corporalidad que dice la existencia y lo hace de un modo similar a como un texto transmite una idea" (p. 138).

De tal manera, las prácticas artísticas realizadas por mujeres han mostrado, replanteado, deconstruido y ampliado lo que podríamos entender por el mundo de la vida, ya que han confrontado los discursos paradigmáticos que dan sustento a la ciencia, la tecnología, la cultura, pero sobre todo de la vida cotidiana, y, por lo tanto, lo que respecta al cuerpo como territorio desde las experiencias de las mujeres.

\section{El cuerpo como territorio y el lenguaje artístico como recurso de la memoria}

"Me gusta citar a Violette le Duc cuando dice: Escribir es desnudarse; si aún el día de hoy se ve mal el strip tease, que slo es el desnudo del cuerpo, se magnifica la idea del desnudo del alma” (De Oyuela, 1997).

En el marco de sus 20 años de fundación, Mujeres en las Artes propone evidenciar el testimonio histórico de nueve mujeres artistas nacidas en el tránsito del siglo XIX e inicios del siglo XX (1830-1912). Dado que algunas de las artistas seleccionadas se apoyan en la literatura, la escritura, las artes escénicas y la pintura como formas de expresión, se emplea, como denominador que las agrupe, la expresión Mujeres Creadoras.

En tal sentido, la propuesta que aquí se expone viene a ser una plataforma estratégica dirigida a evidenciar los aportes de las mujeres creadoras a la cultura hondureña y su papel trascendental en la historiografía nacional. También, y principalmente, pretende reflexionar sobre la importancia que poseen los mecanismos de transgresión en la experiencia corpórea como dispositivos que posibilitaron a las artistas enfrentarse a una sociedad esquiva como la hondureña.

El cuerpo como territorio, como metáfora de la experiencia vivida, lo refiere desde su capacidad perceptiva e intencional (Merleau-Ponty, citado en Trilles, 2004) que se plantea como una manera de anclarse en el mundo y desde la cual hace posible el hablar del otro y de otras subjetividades. Lo 
anterior se vuelve esclarecedor al señalar que el acercamiento al mundo de la vida de las mujeres creadoras permite dar sentido a la experiencia de lo que es llamado olvido, ya que obliga a repensar sobre el tiempo, sobre la huella, la marca de las experiencias corpóreas que dan sentido a los no luga-

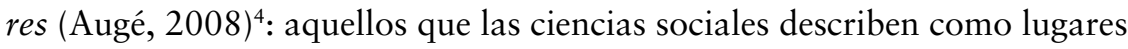
despersonalizados. Por su parte, es a través de la expresión artística como recurso de la memoria que nombran y dan sentido a las vivencias.

El olvido puede pensarse como metáfora del cuerpo, en tanto que vincula las experiencias vividas en el andar de los sucesos perdidos o desaparecidos y dejan una huella ausente en el territorio; por lo tanto, hace referencia al tiempo y la memoria. Vacíos cargados de significados, formados, develados, cartografiados para inventariar y mapear los recuerdos vividos, tanto individuales como colectivos, para de esta manera reinsertarlos en la memoria y recuperar la capacidad de rememorar. Esto es lo que Berdiel (2013) señala como la memoria: aquella que puede crear lo que nunca estuvo ahí, que le da cuerpo a la ausencia.

Recordar el estar en el mundo es dar voz a los testimonios, a las experiencias corpóreas de los sujetos. Es traer a la memoria los actos corporales que expresan la existencia tal y como advierte Ponty (citado en Trilles, 2004): "Lo que yo soy, lo que el mundo es en mí, se dice de mi comportamiento, en mi dirigirme hacia el universo circundante pues la corporalidad es sentido encarnado, expresión primordial o simbolismo" (p.139).

La poeta Clementina Suárez, a través de su vida y su obra, evidencia claramente la magnificencia de la experiencia vivida y lo expresa a partir del lenguaje artístico de la siguiente manera en el poema Rebeldía.

No he venido al mundo / para llorar. No es con lágrimas que se obtiene la alta dimensión del hombre. / No es a que me maltraten ni a que me humillen. / No me arredra la lucha / por más encarnizada que ella sea.

Afianzada tengo el alma / a un rojo encendido de fuerza / que puede maldecir

pero jamás humillarse.

4 Marc Augé (2008) acunó el concepto de los no lugares para referirse a lugares de transitoriedad a los que no se les otorga importancia para ser considerados como lugares. 
No importa que pretenda negar / la luz de mi destino, / que rompa despiadadamente

el encaje del sueño, / que detenga el azogue de mi espejo,

Que me sumerjan en la noche sin adioses, / que con saña me nieguen el pan, la sal y el agua. / No esperen que por ello me doble dócilmente, / aunque la carne sea siempre la carne, / mis entrañas ya casi son de acero / más los que así pretendan / que por mí no teman / que haría falta para ello desconocer / que yo aprendí a cantar con las palabras justas. / Y que he encontrado la verdad en la médula de mis huesos Y que por eso marcho a espaldas de la aurora Como si ella misma naciera en mi costado. (Fragmento del poema Rebeldía. Pineda, 1998, p. 179)

\section{El tránsito de finales del siglo XIX e inicios del siglo XX, $-1830-1912$}

Contextualizando el mundo dentro del cual las mujeres creadoras se desenvolvieron, se subraya que los inicios del siglo XX fueron recibidos por la población hondureña, como señala De Oyuela (2001), en un ambiente de confusión y guerra, periodo en que se agrava el entorno sexista contra la mujer, quien vuelve a ejercer su influencia como antaño, “oculta detrás del trono del varón” (p. 87).

Es importante señalar que muchas de las Mujeres Creadoras se caracterizaron por haber poseído una clara conciencia y, por lo tanto, una visión de mundo en la que su posición política, el papel de la educación y el reconocimiento de los derechos de las mujeres en Honduras fueron puntos importantes y centrales en sus producciones y sus vidas. Por esas razones, rompieron y transgredieron los cánones establecidos para las mujeres de su época.

Honduras se distinguió durante las primeras tres décadas del siglo XX por fuertes convulsiones sociales, sobresaliendo a inicios del siglo el control del caudillismo político y una lucha acérrima por alcanzar la modernidad y el progreso. Barahona (1991) señala que "el caudillismo autoritario imperante en el siglo XIX fue uno de los legados que heredó Honduras a inicios del siglo XX” (p. 278). Los primeros treinta años del siglo pasado fueron 
de inestabilidad política y aguda lucha entre los caudillos autoritarios, cuyo éxito o derrota estaban condicionados a la intervención de Estados Unidos y sus compañías bananeras.

Espacios como los familiares, laborales, políticos o económicos, por mencionar algunos, han sido históricamente separados dicotómicamente para los hombres y para las mujeres. Esta lógica separatista, que es en su seno aberrante pero paradójicamente normalizada en su práctica, no es excluyente para la actividad artística. En esa época, la artista debía resignarse a permitir que su formación y sus ambiciones, su valía y su saber le fueran arrebatados por una cultura que es hombre, por el hombre que es la cultura (De Oyuela, 2001, p. 220).

Creando vivencias futuras es el lema desde el cual MUA se plantea una mirada hacia el porvenir. Un futuro que toma como referencia la evidencia de lo oculto o, mejor dicho, lo ausente; que se presenta en el imaginario social como algo hostil, lejano, ajeno y con pocas y restringidas vías de darse a conocer, de evidenciarse, tanto en lo individual como en lo colectivo.

Se destaca que el cuerpo social no puede manifestarse plenamente sin los recuerdos de aquellos hechos que lo constituyen, por lo que el olvido, entendido como huella de los sucesos desaparecidos, conlleva a pensar un cuerpo social que, a partir de los recuerdos ausentes, describe su estar en el mundo, un conocimiento de su corporalidad, marcada por una huella ausente, violenta y traumática que forma parte de su realidad subjetiva, vivenciada o experienciada. De aquí que, a partir de recuperar la memoria corpórea, se agencien los insumos para acercarse a crear lo que la escritora De Oyuela (2001) llamó un enunciado centrado en la unidad hacia la búsqueda por alcanzar mejores formas de convivencia y de un mejor vivir.

El testimonio histórico de la práctica artística también viene a ser un instrumento para el levantamiento de una cartografía de la memoria corpórea, de los recuerdos obtenidos de las vivencias personales y de la experiencia vivida por otros que se transmiten también en los textos. Así, el testimonio histórico, según Dulong (2004), particularmente el testimonio escrito: "es igual que en su forma oral, la comunicación de una sensibilidad humana a otra, y es por esto que, incluso mediante un texto, implica tanto el cuerpo del testigo como el del destinatario" (p. 97).

Hacer referencia al cuerpo como territorio posibilita la proyección de imágenes que buscan recuperar lo vivido y, de esta manera, sanar las 
experiencias dolorosas desde la comprensión del pasado. Es decir, un espacio desde el cual las personas se identifiquen a sí mismas en el proceso de recuperación de las experiencias de las mujeres creadoras y la toma de conciencia sobre la importancia que tiene el lenguaje artístico en todos los escenarios de la vida, pero, sobre todo, como auxiliar de la memoria con una visión hacia futuro.

El cuerpo como territorio es la edificación desde la cual se construye la subjetividad de cada persona y de las colectividades. Es de esa manera que las mujeres creadoras dan razón de un conocimiento que va más allá de los discursos hegemónicos al replantearse el espacio vivido, desde el cual se llevan a cabo procesos sensitivos, de percepción, de intuición e imaginación que nos permiten combatir el olvido e historizar la memoria para dar sentido al pasado y mirarnos hacia futuro. De tal forma, las experiencias vividas narran lo que Arendt (citada en Crary, 2013) llama "la oscuridad de la existencia abrigada" (p. 19) para indagar y desnudar espacios como el de la familia, la vida privada y la intimidad.

En resumen, a pesar de que han sido muchas las mujeres privadas de posibilidades para dar paso a la fuerza cognitiva del lenguaje, también existieron aquellas que lograron expresarse y, a su vez, vivieron acontecimientos profundamente dolorosos. Las experiencias aprendidas señalan la importancia de las rutas, de los caminos y de los viajes, aquellos que dan sentido al territorio. Por lo tanto, el cuerpo como territorio es una metáfora que agencia la construcción de procesos y prácticas individuales y sociales que redimensionan lo personal como político $^{5}$ y hace posible pensar en relaciones humanas dignas.

5 "Lo personal es político" consigna feminista y nombre de un artículo publicado en 1969, escrito por la feminista estadounidense radical Carol Hanisch. 


\section{Referencias}

Augé, M. (2008). Los no lugares. Espacios del anonimato. España: Editorial Gedisa. Barahona, M. (1991). Evolución histórica de la identidad nacional. Tegucigalpa: Editorial Guaymuras.

Berdiel, O. (2013). La obra de Carlos Muñoz. Lo desaparecido no está ausente. Recuperado de http://psicoanalisisypolitica.blogspot.com/2013/02/la-obra-deoscar-munoz-lo-desaparecido.html

Comisión Interamericana de Derechos Humanos - CIDH, y Organización de los Estados Americanos - OEA (2015). Situación de los derechos bumanos en Honduras. Recuperado de http://www.oas.org/es/cidh/informes/pdfs/ Honduras-es-2015.pdf

Crary, J. (2013). Sobre los finales del sueño: sombras en el resplandor de un mundo 24/7. Recuperado de http://www.estudiosvisuales.net/revista/pdf/num5/ crary_24_7.pdf

De Oyuela, L. (2001). Mujer, Familia y Sociedad. Segunda edición actualizada hasta el 2000. Honduras: Editorial Guaymuras.

Dulong, R. (2004). La implicación de la sensibilidad corporal en el testimonio histórico. Revista de Antropología Social, 13, 97-111. Universidad Complutense de Madrid, España. Recuperado de http://www.redalyc.org/articulo. oa? id=83801304.

OIT (2010). Trabajo decente y juventud. Honduras. Recuperado de http://unpan1. un.org/intradoc/groups/public/documents/icap/unpan045074.pdf

Touraine, A. (2005). Estamos ya en una sociedad de mujeres. El periodista quincenal. Recuperado de http://www.elperiodista.cl/newtenberg/1722/printer-65683.html

Trilles, K. (2004). El cuerpo vivido. Algunos apuntes desde Merleau Ponty. Themata, Revista de Filosofía, 33, 135-140. Recuperado de http://institucional.us.es/revistas/themata/33/13\%20trilles.pdf 